\title{
Lightening up Ruthenium Complexes to Fight Cancer?
}

\author{
Cristina Mari§ and Gilles Gasser* \\ §SCS-Metrohm Award for best oral presentation
}

\begin{abstract}
In medicine, light is used in a medical treatment called photodynamic therapy (PDT) to treat some types of cancer and skin diseases. This technique generally allows for reduced side effects compared to traditional chemotherapy. However, PDT is not fully effective on hypoxic tumors (i.e. lacking oxygen). To overcome this important drawback, photoactivated chemotherapy (PACT) agents have been designed to obtain light-mediated cancer cell death via an oxygen-independent mechanism. Ruthenium complexes have already been and are currently deeply explored as traditional anticancer agents. However, as reported in this short review article, such compounds can also bring novel opportunities in the field of light-mediated cancer treatment. Herein, we report on our findings in the optimization of $\mathrm{Ru}\left({ }^{\prime}\right)$ polypyridyl complexes as PDT and PACT agents for the potential treatment of cancer and, interestingly, also of bacterial infections.
\end{abstract}

Keywords: Light-activated prodrugs · Photoactivated chemotherapy · Photodynamic therapy · Ruthenium

\section{Introduction}

Several drugs currently in use against cancer are not (fully) selective for cancer cells. Cisplatin and its derivatives Oxaliplatin and Carboplatin, which are employed in almost $50 \%$ of the chemotherapeutic treatments against cancer, are typical examples of this class of unselective compounds. These Pt-based drugs are able to covalently crosslink two strands of helical DNA and hence to prevent cell replication. Such a mechanism leads eventually to cell death. This mechanism of action strongly affects cancer cells, which are known to divide more frequently than normal cells and have a faster metabolism. On the other hand, there are several kind of healthy fast dividing cells in the human organism (e.g. hair follicles, bone marrow and cells lining the gastrointestinal tract), which are also damaged by Cisplatin and its derivatives. ${ }^{[1]}$ This fact is responsible for the severe side effects (e.g. nephrotoxicity, neurotoxicity, ototoxicity, nausea, vomiting, etc.) that patients can encounter

\footnotetext{
${ }^{*}$ Correspondence: Prof. Dr. G. Gasser

University of Zurich

Department of Chemistry

Winterthurerstrasse 190

$\mathrm{CH}-8057$ Zurich

Tel.: +41446354630

E-mail: gilles.gasser@chem.uzh.ch
}

during chemotherapeutic treatments with these compounds. ${ }^{[2]}$

To overcome this selectivity problem, several researchers have envisaged the use of a prodrug approach..$^{[3,4]}$ A prodrug is a compound administered to a patient that, ideally, does not have any biological effect. An activation must occur to transform the prodrug into the active species (i.e. the drug). When the prodrug is localized to a specific tissue, the requirement for its activation allows for reduction of the systemic side-effects of the parent drug. The formation of the active species can be triggered by a stimulus of two different origins: an internal stimulus or an external one. In the first case, the prodrug can be activated due to a change of $\mathrm{pH}$ (i.e. the $\mathrm{pH}$ of tumors is usually more acidic than its environment ${ }^{[5]}$ or due to an enzymatic reaction. However, an important drawback of this approach is that there is no actual control on the activation of the prodrug. If the conditions necessary to form the active species are met, the prodrug will be activated although it might not be at the desired site of action (i.e. in the tumor tissues in the case of an anticancer prodrug). This unpredictable behavior can lead to undesired side effects. On the contrary, the unwanted activation of the prodrug can be overcome when an external stimulus such as light irradiation, ${ }^{[6-8]}$ variation of the temperature, ${ }^{[8,9]}$ ultrasound or magnetic field ${ }^{[10]}$ is employed. Using such an approach, the medical doctor has a complete spatial and temporal control on the formation of the actual toxic species. A medical technique requiring the light activation of a prodrug (i.e. a photosensi- tizer, PS) is already applied in the clinic for the treatment of certain skin-related diseases, age-related macular degeneration and cancer. ${ }^{[11]}$ This technique is called photodynamic therapy (PDT). PDT relies on an oxygen-dependent mechanism to induce light-mediated cell death. This treatment exploits the concerted action of three components: a PS, light and oxygen. Their synergistic activity leads to the generation of oxidative stress inside the cell, which can eventually result in cell death. More precisely, the PS is first administered to a patient. Upon light irradiation at a specific wavelength, the PS reaches its triplet excited state, PS*. At this moment, a proton or electron transfer from the PS* to the surrounding biological substrates can take place (Type I reaction). This leads to the formation of radicals and reactive oxygen species (ROS) and, consequently, to strong oxidative stress for the cell. At the same time, an energy transfer from the PS* to oxygen in its triplet ground state $\left({ }^{3} \mathrm{O}_{2}\right)$ can occur (Type II reaction). This leads to the formation of singlet oxygen $\left({ }^{1} \mathrm{O}_{2}\right)$, a very reactive form of oxygen. ${ }^{1} \mathrm{O}_{2}$, due to its high reactivity, has a very short diffusion distance in a biological environment $(0.02$ $\mu \mathrm{m}) .{ }^{[12,13]}$ As a consequence, its toxic effect will be exerted just in the very proximity of the irradiated area. Most of the approved PSs act via this second mechanism. ${ }^{[14]}$ However, a known drawback of this technique is its lack of efficiency on cancers characterized by low oxygen tension (i.e. hypoxia). ${ }^{[15]}$ Such an environment is frequently encountered in some tumors due to their inefficient blood circulation. As a 
consequence, PDT was shown to be not very effective on these types of cancer. To overcome this problem, researchers have developed compounds that display light-induced toxicity via an oxygen-independent mechanism. Such compounds are generally referred to as photoactivated chemotherapy (PACT) agents. Several activation pathways have been employed to produce the toxic species. This includes ligand exchange or the photo-release of biologically active compounds. ${ }^{[16-19]}$

Over the past few years, our group, in collaboration with several colleagues, has investigated the use of metal complexes in the fields of PDT and PACT. ${ }^{[20-28]}$ In particular, we focused our attention on $\mathrm{Ru}(\mathrm{II})$ complexes. Ruthenium compounds are nowadays considered as the potential successors to Pt-based anticancer drugs. ${ }^{[29,30]}$ Indeed, two complexes (NAMI-A and NKP1339) are currently in phase II clinical trials and a third one (RAPTA-C) is currently in pre-clinical evaluation. ${ }^{[31-34]} \mathrm{Ru}$ complexes are characterized by a very versatile chemistry, a generally lower systemic toxicity than Pt-based compounds and a higher tumor accumulation. [29] This last important property is assumed to be the consequence that $\mathrm{Ru}$ complexes are mimicking iron and are therefore transported into cells by transferrin receptor-mediated endocytosis. ${ }^{[35,36]}$ A higher accumulation into cancer cells compared to healthy cells results from the higher need for iron of cancer cells (i.e. to sustain their faster metabolism). Of note, the prodrug approach is not a novelty with Ru complexes, since it is suggested that the activity of both NAMI-A and NKP1339 is triggered by an initial reduction from $\mathrm{Ru}(\mathrm{III})$ to $\mathrm{Ru}$ (II) inside the hypoxic environment of cancer cells (activation by reduction). ${ }^{[29,33]}$ Our group decided to focus its attention on a different and very promising class of $\mathrm{Ru}$ complexes, namely substitutionally inert $\mathrm{Ru}(\mathrm{II})$ polypyridyl complexes. This class of compounds has been thoroughly studied because of their favorable physico-chemical properties. They are characterized by very easily exploitable $\mathrm{Ru}(\mathrm{II}) / \mathrm{Ru}(\mathrm{III})$ redox chemistry and absorbance in the visible spectrum, long-lived triplet metal-toligand charge transfer ( ${ }^{3}$ MTLC) transfer state and emission with large Stokes shift. For all these reasons, $\mathrm{Ru}$ complexes were shown to perform very well in dye-sensitized solar cells (DSSCs) applications. ${ }^{[37]}$ These characteristics made them also suitable for bio-imaging purposes. ${ }^{[38,39]}$ In addition to these applications, the potential of such compounds have also been studied in the field of medicinal chemistry. ${ }^{[40-42]}$ This field was pioneered by Dwyer and coworkers, who first investigated the biological activity of polypyridyl transition metal complexes. ${ }^{[43]}$ Furthermore, this class of compounds has been studied since decades as DNA intercalators. This application was first discovered by Barton and co-workers, who showed the light-switch behavior of such compounds. ${ }^{[4,45]}$ Over the last years, the ability of $\mathrm{Ru}$ polypyridyl complexes to produce ${ }^{1} \mathrm{O}_{2}$ upon irradiation was also investigated and their potential application in PDT to kill cancer cells evaluated. Concurrently, several groups have focused their efforts to obtain light-activatable anticancer compounds based on ruthenium. An extensive description of the recent findings in these fields of research was recently reviewed by our group and will not be discussed in this article. ${ }^{[19]}$ Instead, we will describe our recent discoveries on the potential application of Ru complexes as both PDT and PACT agents for the treatment of cancer and bacterial infections (see Fig. 1 for the structures of the Ru complexes discussed herein). ${ }^{[22,25,27,46,47]}$

\section{Ruthenium Complexes as PDT Agents}

Nowadays, nearly all PSs that are approved for PDT treatments are based on a tetrapyrrolic scaffold like porphyrins, phthalocyanines or chlorins. ${ }^{[48,49]}$ The reason why these structures dominate this field of research is relatively simple. These compounds meet most of the characteristics of an ideal PS. Indeed, they have an available triplet excited state, allowing for energy transfer to ${ }^{3} \mathrm{O}_{2}$. They can also be ex- cited with light at wavelengths above 600 $\mathrm{nm}$, which allows for deep tissue penetration. ${ }^{[50,51]}$ Furthermore, they are known for higher accumulation in cancer cells compared to healthy cells. Nonetheless, despite these 'ideal' characteristics, the discovery of novel PSs with even better properties is required. Indeed, the current tetrapyrrolic PSs are generally characterized by a nontrivial synthesis and purification as well as low water solubility. In addition, some of these compounds can undergo photobleaching in the presence of ${ }^{1} \mathrm{O}_{2} \cdot{ }^{[52]}$ From the clinical point of view, one of the most important problems of such compounds comes from the photosensitivity observed in patients, even up to several weeks after PS administration. This is due to the fact that part of the PS administered to the patient still ends up in healthy tissue. ${ }^{[53]}$ Currently, research is ongoing to develop novel PSs with improved characteristics compared to the approved ones. The opportunity to use metal complexes for this application has also been explored. ${ }^{[54]}$ In particular, $\mathrm{Ru}(\mathrm{II})$ complexes have attracted a lot of interest due to their favorable photophysical properties. ${ }^{[19,55]}$ In our group, we envisaged coupling the DNA intercalating ability of $\mathrm{Ru}(\mathrm{II})$ polypyridyl complexes with their ${ }^{1} \mathrm{O}_{2}$ production. The final goal was to have a compound which strongly interacts with DNA, so that ${ }^{1} \mathrm{O}_{2}$ is produced in very close proximity to the genetic material and can induce the highest damage. We focused our attention on the $\left[\mathrm{Ru}(\text { bipy) })_{2} \mathrm{dppz}\right]^{2+}$ scaffold (where bipy

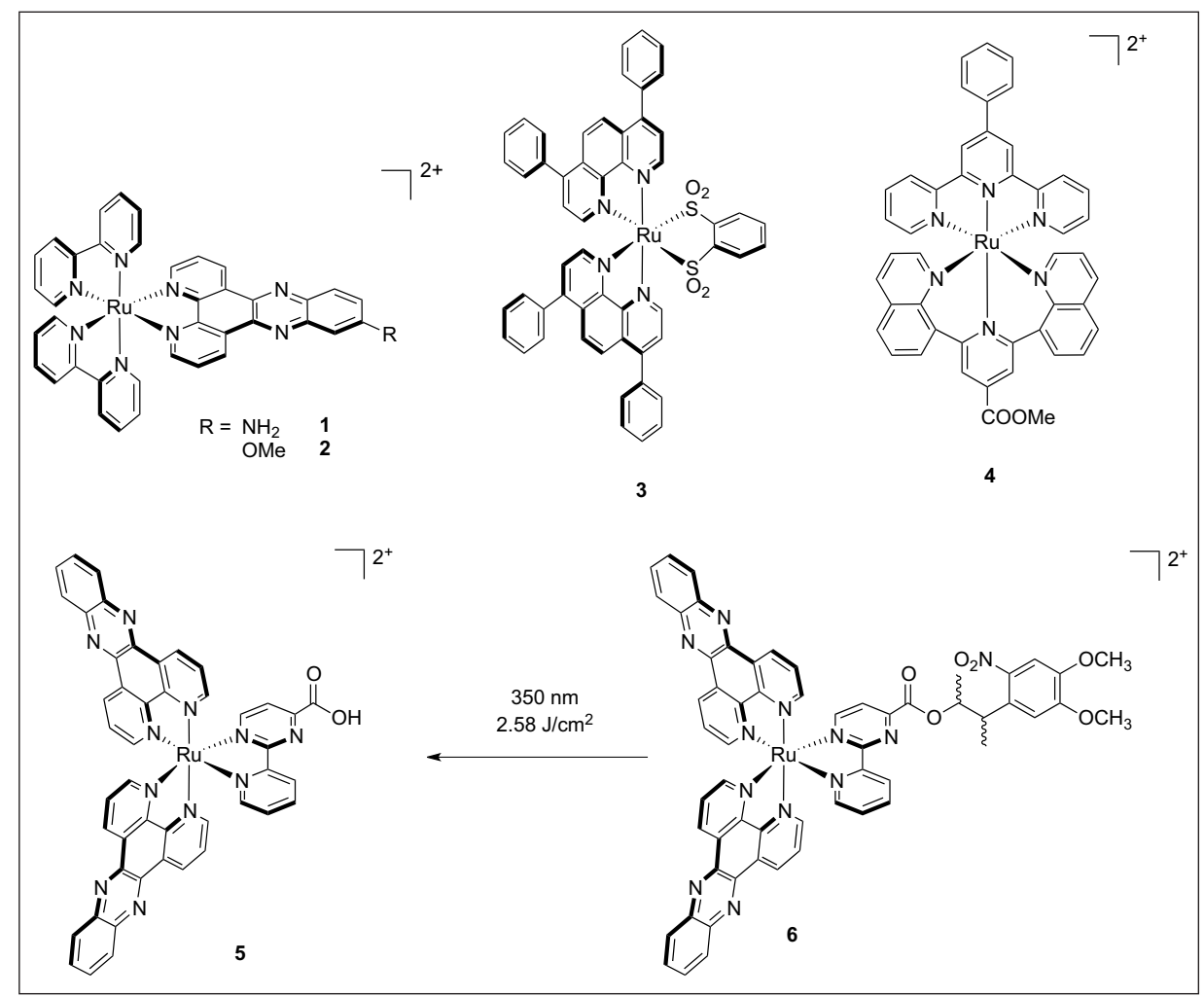

Fig. 1. Structures of $R u(I I)$ complexes discussed in this review. 
$=2,2^{\prime}$-bipyridyl and dppz $=$ dipyrido[3,2$\mathrm{a}: 2^{\prime}, 3^{\prime}$-c]phenazine) due to the pioneer work of Barton et al., who reported the high intercalating affinity of such compounds for DNA. ${ }^{[44,45]}$ More specifically, we synthesized six derivatives with different functional groups in position 7 of the dppz ligand (Fig. 1 shows the structure of the two most active compounds $\mathbf{1}$ and 2). By spectroscopic evaluation, we could confirm that the DNA affinity of our complexes remained very high and comparable with the unsubstituted analog $\left(\mathrm{K}_{\mathrm{b}} \sim 10^{6} \mathrm{M}^{-1}\right.$ per nucleotide), and this despite the presence of the substituents on the intercalating ligand. As also suggested by density functional theory (DFT) calculations, ${ }^{1} \mathrm{O}_{2}$ was produced very efficiently. ${ }^{1} \mathrm{O}_{2}$ quantum yields were then determined using two methods reported in literature, namely the direct detection of the luminescence of ${ }^{1} \mathrm{O}_{2}$ at $1270 \mathrm{~nm}$ and by trapping ${ }^{1} \mathrm{O}_{2}$ into a stable adduct. Measurements were performed in two different solvents (PBS and acetonitrile) and at two wavelengths (350 $\mathrm{nm}$ and $420 \mathrm{~nm}$ ). Both methods indicated a generally high ${ }^{1} \mathrm{O}_{2}$ quantum yield for the two complexes in acetonitrile (73\% for $\mathbf{1}$ and $70 \%$ for $\mathbf{2}$, respectively, at $420 \mathrm{~nm}$ with the detection of ${ }^{1} \mathrm{O}_{2}$ luminescence). On the other hand, the yields were much lower in aqueous solutions. This phenomenon is explained by the so-called lightswitch behavior that characterizes these compounds. ${ }^{[44,45]}$ In aqueous environment, the excited state of the complexes is quenched by hydrogen bonding with water. Therefore, energy transfer to $\mathrm{O}_{2}$ cannot occur. On the contrary, in lipophilic environment (organic solvents or when intercalated into DNA), the non-radiative quenching cannot take place. This increases the lifetime of the excited state, allowing for ${ }^{1} \mathrm{O}_{2}$ formation. High ${ }^{1} \mathrm{O}_{2}$ quantum yields in acetonitrile indicate that the complexes could produce ${ }^{1} \mathrm{O}_{2}$ when located in lipophilic cell compartments. With these promising characteristics, we then assessed the activity of our compounds on cells. The cytotoxicity of the complexes in the dark was evaluated on normal fetal lung fibroblast MRC-5 and cervical cancer HeLa cells upon $48 \mathrm{~h}$ incubation (see Table 1A). Both complexes were found to be non toxic up to $100 \mu \mathrm{M}$ concentration in the dark, as required for a PS. Phototoxicity was evaluated on both cell lines upon $4 \mathrm{~h}$ incubation, followed by light irradiation at $350 \mathrm{~nm}\left(2.58 \mathrm{~J} / \mathrm{cm}^{2}\right)$ or $420 \mathrm{~nm}(9.27 \mathrm{~J} /$ $\mathrm{cm}^{2}$ ). The resulting phototoxicity on HeLa cells was found to be very promising for both compounds, with $\mathrm{IC}_{50}$ of $2.0 \mu \mathrm{M}$ and $5.5 \mu \mathrm{M}$ for 1 and 2 respectively at $420 \mathrm{~nm}$ (see Table 1A). In PDT, however, the potential of a compound is also described by its phototoxic index (PI). The PI is the ratio of the $\mathrm{IC}_{50}$ of a compound in the dark on

Table 1. $I C_{50}$ values for all the compounds discussed in this review.

\begin{tabular}{|c|c|c|c|c|c|c|}
\hline \multirow[t]{3}{*}{$\mathbf{A}$} & \multicolumn{6}{|c|}{$\mathrm{IC}_{50}[\mu \mathrm{M}]$} \\
\hline & \multicolumn{5}{|c|}{$\mathrm{HeLa}$} & MRC-5 \\
\hline & \multicolumn{2}{|l|}{ Dark 48 h } & $\begin{array}{l}\text { Light } 4 \mathrm{~h} \\
(350 \mathrm{~nm})^{\mathrm{a}}\end{array}$ & \multicolumn{2}{|c|}{ Light $4 \mathrm{~h}(420 \mathrm{~nm})^{\mathrm{b}}$} & Dark $48 \mathrm{~h}$ \\
\hline 1 & \multicolumn{2}{|l|}{$>300$} & $25.1^{ \pm 7.6}$ & \multicolumn{2}{|l|}{$2.0^{ \pm 0.9}$} & $>100$ \\
\hline 2 & \multicolumn{2}{|l|}{$235.5^{ \pm 24.7}$} & $9.0^{ \pm 1.4}$ & \multicolumn{2}{|l|}{$5.5^{ \pm 0.7}$} & $>100$ \\
\hline \multirow[t]{3}{*}{ B } & \multicolumn{6}{|c|}{$\mathrm{IC}_{50}[\mu \mathrm{M}]$} \\
\hline & \multicolumn{5}{|c|}{ HeLa } & MRC-5 \\
\hline & \multicolumn{2}{|l|}{ Dark 48 h } & Dark $4 \mathrm{~h}$ & \multicolumn{2}{|c|}{ Light $4 \mathrm{~h}(420 \mathrm{~nm})^{\mathrm{c}}$} & Dark 48 h \\
\hline 3 & \multicolumn{2}{|l|}{$5.7 \pm 0.7$} & $49.7 \pm 10.1$ & \multicolumn{2}{|c|}{$0.62 \pm 0.28$} & $15.6^{ \pm 2.7}$ \\
\hline 4 & \multicolumn{2}{|l|}{$>100$} & $>100$ & \multicolumn{2}{|c|}{$25.3^{ \pm 4.7}$} & $>100$ \\
\hline \multirow[t]{2}{*}{ C } & \multicolumn{6}{|c|}{$\mathrm{IC}_{50}[\mu \mathrm{M}]^{\mathrm{d}}$} \\
\hline & HeLa & MCF7 & $\mathrm{U} 2 \mathrm{OS}$ & A2780 & A2780-CP70 & MRC-5 \\
\hline 5 & $10.0^{ \pm 1.3}$ & $4.3^{ \pm 0.1}$ & $13.5^{ \pm 2.5}$ & $2.8^{ \pm 0.1}$ & $4.0^{ \pm 1.2}$ & $15.1^{ \pm 2.2}$ \\
\hline cisplatin & $11.5^{ \pm 2.9}$ & $1.8^{ \pm 0.3}$ & $11.8^{ \pm 1.7}$ & $2.9 \pm 0.6$ & $13.8^{ \pm 3.0}$ & $7.9^{ \pm 1.2}$ \\
\hline \multirow[t]{3}{*}{ D } & \multicolumn{6}{|c|}{$\mathrm{IC}_{50}[\mu \mathrm{M}]$} \\
\hline & \multicolumn{2}{|c|}{ HeLa } & \multicolumn{3}{|c|}{ U2OS } & MRC-5 \\
\hline & Dark $48 \mathrm{~h}$ & $\begin{array}{l}\text { Light } 4 \mathrm{~h} \\
(350 \mathrm{~nm})^{\mathrm{a}}\end{array}$ & Dark 48 & Ligh & $4 \mathrm{~h}(350 \mathrm{~nm})^{\mathrm{a}}$ & Dark $48 \mathrm{~h}$ \\
\hline 6 & $85.5^{ \pm 5.8}$ & $17.0 \pm 0.8$ & $>100$ & 17.2 & & $85.3^{ \pm 0.2}$ \\
\hline
\end{tabular}

${ }^{\mathrm{a}}-2.58 \mathrm{~J} / \mathrm{cm} 2{ }^{\mathrm{b}}-9.27 \mathrm{~J} / \mathrm{cm} 2 ;^{\mathrm{c}}-6.95 \mathrm{~J} / \mathrm{cm} 2 ;^{\mathrm{d}}$ - dark, $48 \mathrm{~h}$ incubation.

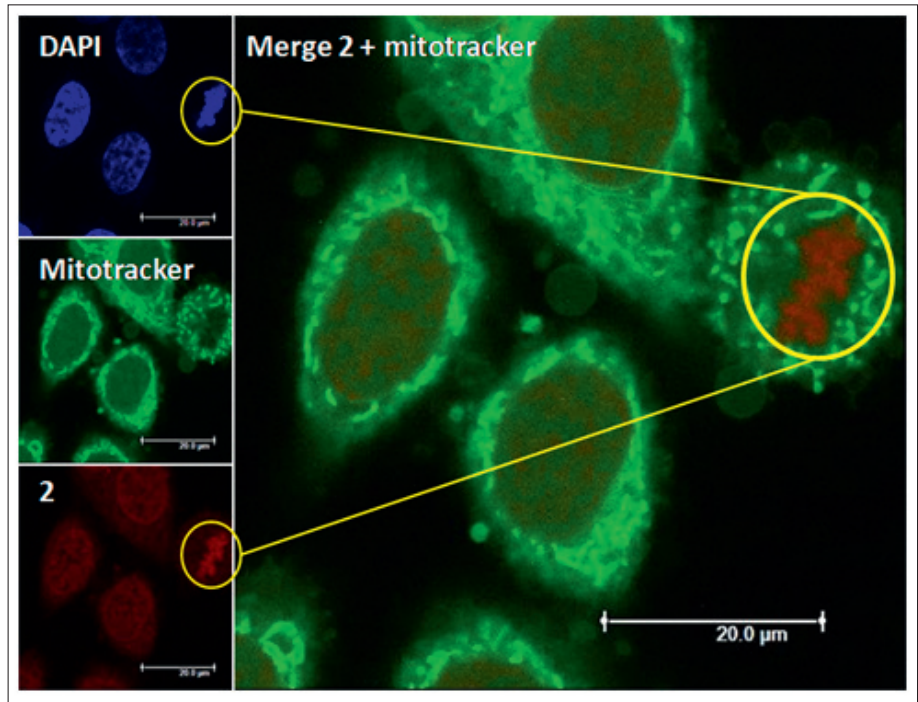

Fig. 2. Cellular localization of complex 2. Confocal microscopy localization experiments on HeLa cells treated for $2 \mathrm{~h}$ with $100 \mu \mathrm{M}$ of complex 2 (excitation at $488 \mathrm{~nm}$, emission above $600 \mathrm{~nm}$, bottom left) and stained with DAPI (nuclear staining, top left) and with Mitotracker green (mitochondrial staining middle left); in the yellow circle a representative example of the different localization of $\mathbf{2}$ and Mitotracker green (picture on the right). Reproduced with permission from ref. [22], (c) 2014 Wiley-VCH Verlag GmbH \& Co. KGaA, Weinheim.

its $\mathrm{IC}_{50}$ upon light irradiation. This value indicates the increment of potency of a PS when irradiated. Upon evaluation of the maximum dark toxicity for the active compounds, we could determine an impressive
PI of $>150$ for $\mathbf{1}$, indicating a light-induced increment in the toxicity of two orders of magnitude. Complex $\mathbf{2}$ displayed a more modest PI of 43. To gain an insight into the mechanism of action of the two com- 
plexes, cellular localization was evaluated by confocal microscopy. Compound $\mathbf{2}$ was found to have a very good nuclear accumulation on HeLa cells, when incubated for $2 \mathrm{~h}$ at a concentration of $100 \mu \mathrm{M}$ (Fig. 2).

In contrast, the luminescence of $\mathbf{1}$ was barely detectable in living cells. This behavior can be ascribed to its very low emission quantum yields $\left(\Phi_{\mathrm{em}}=0.1\right)$. To shed light on the cellular localization of $\mathbf{1}$, we employed an analytical technique called high resolution continuum source atomic absorption spectrometry (HR-CS AAS) that allows for trace determination of metals in a matrix. This technique confirmed high Ru uptake for both 1 and 2 (1.08 and 1.76 nmol per mg of protein, respectively).[56] Furthermore, upon organelles isolation, we could confirm the nuclear accumulation of the two complexes, corroborating the data derived from luminescence studies for 2. These findings gave us a strong hint that our complexes could damage DNA. To support this hypothesis, we performed plasmid DNA photocleavage experiments. Both complexes were found to induce nicks in the supercoiled form of the plasmid upon light activation at $420 \mathrm{~nm}(9.27$ $\mathrm{J} / \mathrm{cm}^{2}$ ) in a dose dependent manner. All in all, compounds $\mathbf{1}$ and $\mathbf{2}$ are able to induce cell death upon light activation in an oxygen dependent way, damaging cells at the nuclear level. A thorough biological evaluation of the effect of $\mathbf{2}$ on nuclear DNA is currently on-going and will be published in the near future.

As mentioned above, Ru complexes were extensively explored for DSSCs applications, taking advantage of their long excited-state lifetimes and visible light absorption. Interestingly, these characteristics are also very important for a PS. Consequently, our group in collaboration with the one of Prof. Leone Spiccia at Monash University designed two Ru complexes for PDT applications, inspired from the structures which are employed in DSSCs. ${ }^{[27]}$ We therefore synthesized 3 (namely $[\mathrm{Ru}(1,10$ diphenylphenanthroline) 1,2 -benzenedithiol], Fig. 1), in which the dithiol ligand is known to induce a red shift in the absorbance. In addition, compound $\mathbf{4}$, whose structure is reported in Fig. 1, was designed since tridentate ligands lead normally to a broadening in the absorbance across the visible spectrum. The two compounds were incubated in HeLa cells for $4 \mathrm{~h}$ to study their cellular localization, which was assessed via inductively coupled plasma mass spectrometry (ICP-MS). 3 was found to localize preferentially in mitochondria (67\% of total Ru uptake). This finding was also confirmed by confocal microscopy (Fig. 3). Interestingly, 4 was shown to accumulate in the nucleus, and $50 \%$ of $\mathrm{Ru}$ cellular content was detected there.
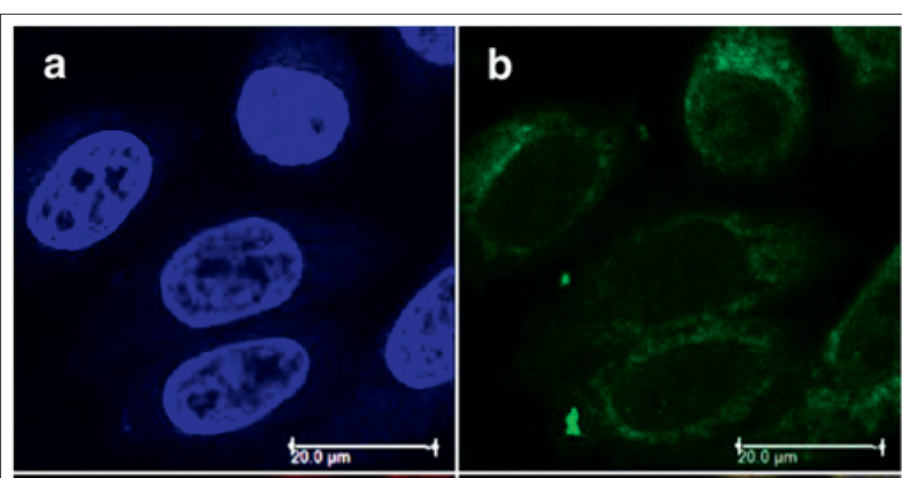

Fig. 3. Fluorescence confocal microscopy images of HeLa cells incubated with 40 $\mu \mathrm{M}$ of 3 for $4 \mathrm{~h}$ : (a) DAPI staining, (b) Mitotracker green FM staining, (c) visualization of 3 by excitation at $405 \mathrm{~nm}$, (d) overlay of a-c. Reprinted with permission from ref. [27], (C) 2014
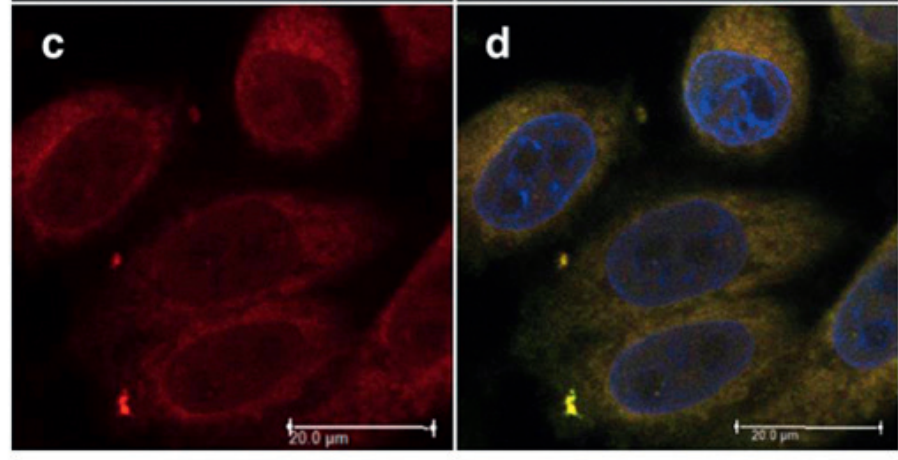

American Chemical Society.
The complexes were then tested on HeLa cells (see Table 1B). A strong phototoxic activity for $\mathbf{3}$ was observed when irradiated at $420 \mathrm{~nm}\left(6.95 \mathrm{~J} / \mathrm{cm}^{2}\right)$. A very promising $\mathrm{IC}_{50}$ of $620 \mathrm{nM}$ was reached upon light activation, with a PI of 80 . Compound 4 was showing a modest toxicity in the same irradiation conditions, with $\mathrm{IC}_{50}=25.3 \mu \mathrm{M}$ and PI $>4$. In addition, the potential of the two compounds as antimicrobial PDT (aPDT) agents was evaluated. The use of PDT to kill bacteria is very advantageous, since it could overcome the outburst of resistance to the available antibiotics. A significant advantage of aPDT compared to the established antibiotics is the absence of a defined cellular target. Therefore, the development of a resistance mechanism is less likely to happen. Two strains of bacteria were used for this experiment, namely the Gram-(-) Staphylococcus aureus and the Gram-(+) Escherichia coli. Interestingly, complex 4 at a concentration of $50 \mu \mathrm{M}$ and with a light dose of $8 \mathrm{~J} / \mathrm{cm}^{2}$ at $420 \mathrm{~nm}$ could reduce the viability of $S$. aureus of $>6 \log _{10}$ and of E. coli of $>4 \log _{10}$. This behavior is very favorable, since normally Gram-(-) bacteria are more resistant to treatment. Interestingly, 3 was active against $S$. $a u$ reus $\left(>6 \log _{10}\right)$, but not harmful for $E$. coli.

\section{Ruthenium Complexes as PACT Agents}

As mentioned above, PDT suffers from an important limitation: the dependence of its mechanism of action on oxygen. Several types of cancer are known to be characterized by an hypoxic core, compromising therefore the activity of PDT. ${ }^{[15]}$ Researchers have investigated a great variety of compounds with light-induced activity, but whose mechanism of toxicity does not rely on oxygen, to apply them as PACT agents. ${ }^{[6,57,58]}$ Among the different (metalbased) compounds exploited in this field of research, Ru complexes have played an important role, as recently reviewed by our group. ${ }^{[19]}$ We also actively contributed to the field by designing, to the best of our knowledge, the first substitutionally inert $\mathrm{Ru}$ PACT prodrug, whose activity can be turned on via light exposure. More specifically, we first discovered the impressive cytotoxic behavior of a novel $\mathrm{Ru}(\mathrm{II})$ complex, namely $\left[\mathrm{Ru}(\mathrm{dppz})_{2} \mathrm{CppH}\right]^{2+}$ (5) (where $\mathrm{CppH}=2-(2$-pyridyl)pyrimidine4-carboxylic acid, see Fig. 1). ${ }^{[46]}$ This compound showed very good stability in human blood plasma as well as good DNA intercalating affinity. Toxicity screening on different cancerous cell lines (see Table 1C) highlighted a very promising activity of the compound, with $\mathrm{IC}_{50}$ values comparable or even lower than cisplatin. Interestingly, the compound was active even on the cisplatin-resistant ovarian cancer A2780-CP70 cell line. On the other hand, the toxicity on non cancerous MRC5 cells was lower than that of cisplatin. The mechanism of action of the compound was also elucidated using different biological experiments. The compound was found to preferentially localize in mitochondria using confocal microscopy. Fig. 4 shows a clear overlay of the emissions of the $\mathrm{Ru}$ complex and of the commercially available dye Mitotracker green. 


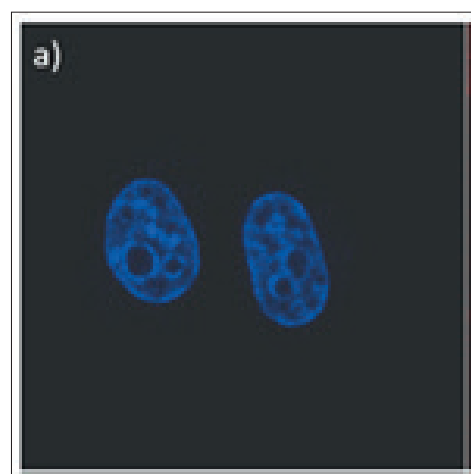

b)

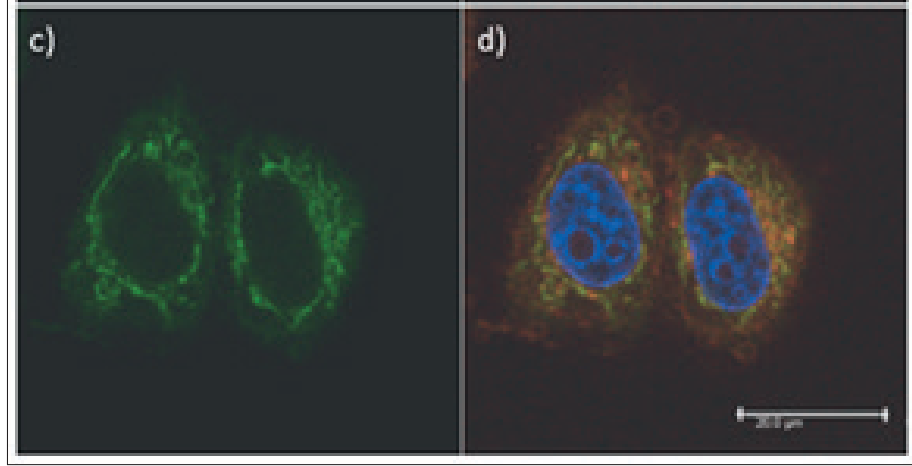

Fig. 4. Fluorescence confocal microscopy images of HeLa cells incubated with 5 $(20 \mu \mathrm{M})$ for $2 \mathrm{~h}$ and Mitotracker green FM for 45 min: (a) DAPI staining; (b) cellular staining of $\mathbf{5}$; (c) Mitotracker green FM staining; and (d) the overlay image. Reprinted with permission from ref. [46], (C) 2012 American Chemical Society.
The localization of compound $\mathbf{5}$ was also confirmed by HR-CS AAS, from which the amount of $\mathrm{Ru}$ in mitochondria was estimated as $68 \%$ of the total uptake. Further evaluations by means of several biological assays suggested that apoptosis was playing a major role in the mechanism of cell death. This was found to be related to the impairment of the mitochondrial membrane potential. However, cell death was found to be independent from ROS production.

A second step in this project was to study the role of the different ligands in the activity of compound 5. ${ }^{[47]}$ In a small structure-activity relationship study, 13 derivatives of $\mathbf{5}$ were synthesized by variation of the ligands around the $\mathrm{Ru}$ center or by the addition of targeting peptides to modify the initial cellular localization of $\mathbf{5}$. Surprisingly, $\mathbf{5}$ was found to be still the most toxic among all derivatives. Interestingly, this study highlighted how the presence of the carboxylic functionality is absolutely required for the toxicity of $\mathbf{5}$. The activity of 5 indeed significantly decreased if an ester moiety was replacing the carboxylic acid moiety. We therefore decided to derivatize the carboxylic acid function with a photolabile functional group, namely 3-(4,5-dimethoxy-2-nitrophenyl)-2-butyl to allow for the control of the toxicity of 5. ${ }^{[25]}$ Hence, we obtained the photoactivable complex 6 (Fig. 1), characterized by negligible or even absent toxicity in the dark on three different cell lines, namely MRC-5, HeLa and bone cancer U2OS cells, up to $48 \mathrm{~h}$ incubation (see Table 1-D). When light at $350 \mathrm{~nm}\left(2.58 \mathrm{~J} / \mathrm{cm}^{2}\right)$ was applied to the cells after $4 \mathrm{~h}$ incubation with $\mathbf{6}$, the initial toxicity of $\mathbf{5}$ was fully restored, confirming hence the potential of the strategy employed.

\section{Conclusion}

The three examples reported above demonstrate the great potential of metal complexes, and in particular of $\mathrm{Ru}$ (II) compounds, as light-mediated anticancer and antibacterial prodrugs. On the other hand, there are still several issues which need to be addressed. One of the most important problems that will need to be overcome is the wavelength of activation. In order to treat solid tumors, millimeter- or, ideally, centimeter-scale penetration of the light through tissue is required. Red and near IR light penetrates human tissues deeper than light at shorter wavelength, allowing for better activation of the prodrug. [50] Furthermore, light in this part of the spectrum is less harmful for tissues. Nowadays, most of the reported metal-based PSs are activated with blue or green light. This activation can be acceptable for particular kinds of superficial cancer such as melanoma. ${ }^{[59,60]}$ On the other hand, in order for metal-based PSs candidates to compete with the currently approved PSs, it is definitively necessary to develop compounds which are activatable at higher wavelengths. Another important point which will need to be addressed in the future is the translation of the interesting results obtained on a cellular level into in vivo studies. Such studies will shed light on the full potential of these light-activatable metalbased prodrugs.

\section{Acknowledgements}

This work was financially supported by the Swiss National Science Foundation (SNSF Professorships PP00P2_133568 and PP00P2_157545 to G.G.), the University of Zurich (G.G.), the Stiftung für Wissenschaftliche Forschung of the University of Zurich (G.G.), the UBS Promedica Stiftung (G.G.) and the Forschungskredit of the University of Zurich (C.M.). C.M. thanks the Swiss Chemical Society (SCS) for the 2015 SCS-Metrohm Award for the best oral presentation.

Received: January 20, 2015

[1] A. V. Schally, A. Nagy, Eur. J. Endocrinol. 1999, 141,1 .

[2] P. Kay, Semin. Oncol. Nurs. 2006, 22, 1.

[3] J. Rautio, 'Prodrugs and Targeted Delivery: Towards Better ADME Properties', Wiley-VCH Verlag GmbH \& Co. KGaA: Weinheim, 2011.

[4] J. Rautio, H. Kumpulainen, T. Heimbach, R. Oliyai, D. Oh, T. Jarvinen, J. Savolainen, Nature Rev. Drug Discov. 2008, 7, 255.

[5] M. J. Clarke, Coord. Chem. Rev. 2003, 236, 209.

[6] N. A. Smith, P. J. Sadler, Phil. Trans. R. Soc. A 2013, 371, 20120519

[7] D. Kessel, J. Reiners, Isr. J. Chem. 2012, 52, 674.

[8] M. Nakayama, J. Akimoto, T. Okano, J. Drug Target. 2014, 22, 584 .

[9] M. Bikram, J. L. West, Expert Opin. Drug Deliv. 2008, 5, 1077.

[10] S. Laurent, A. A. Saei, S. Behzadi, A. Panahifar, M. Mahmoudi, Expert Opin. Drug Deliv. 2014, $11,1449$.

[11] D. E. J. G. J. Dolmans, D. Fukumura, R. K. Jain, Nat. Rev. Cancer 2003, 3, 380.

[12] J. Moan, K. Berg, Photochem. Photobiol. 1991, $53,549$.

[13] A. P. Castano, T. N. Demidova, M. R. Hamblin, Photodiagn. Photodyn. 2004, 1, 279.

[14] K. Plaetzer, B. Krammer, J. Berlanda, F. Berr, T. Kiesslich, Laser Med. Sci. 2009, 24, 259.

[15] A. L. Harris, Nat. Rev. Cancer 2002, 2, 38

[16] E. C. Glazer, Isr. J. Chem. 2013, 53, 391.

[17] T. Respondek, R. Sharma, M. K. Herroon, R. N. Garner, J. D. Knoll, E. Cueny, C. Turro, I. Podgorski, J. J. Kodanko, ChemMedChem. 2014, 9, 1306.

[18] M. A. Sgambellone, A. David, R. N. Garner, K. R. Dunbar, C. Turro, J. Am. Chem. Soc. 2013, $135,11274$.

[19] C. Mari, V. Pierroz, S. Ferrari, G. Gasser, Chem. Sci. 2015, DOI: 10.1039/C4SC03759F

[20] P. M. Antoni, A. Naik, I. Albert, R. Rubbiani, S. Gupta, P. Ruiz-Sanchez, P. Munikorn, J. M. Mateos, V. Luginbuehl, P. Thamyongkit, U. Ziegler, G. Gasser, G. Jeschke, B. Spingler, Chem. Eur. J. 2015, 21, 1179.

[21] A. Naik, R. Rubbiani, G. Gasser, B. Spingler, Angew. Chem., Int. Ed. 2014, 53, 6938.

[22] C. Mari, V. Pierroz, R. Rubbiani, M. Patra, J. Hess, B. Spingler, L. Oehninger, J. Schur, I. Ott, L. Salassa, S. Ferrari, G. Gasser, Chem. Eur. J. 2014, 20, 14421.

[23] A. Leonidova, V. Pierroz, R. Rubbiani, Y. Lan, A. G. Schmitz, A. Kaech, R. K. O. Sigel, S. Ferrari, G. Gasser, Chem. Sci. 2014, 5, 4044.

[24] A. Leonidova, V. Pierroz, R. Rubbiani, J. Heier, S. Ferrari, G. Gasser, Dalton Trans. 2014, 43, 4287

[25] T. Joshi, V. Pierroz, C. Mari, L. Gemperle, S. Ferrari, G. Gasser, Angew. Chem., Int. Ed. 2014, $53,2960$.

[26] T. Joshi, G. Gasser, Synlett 2015, DOI: 10.1055/ s-0034-1379426. 
[27] A. Frei, R. Rubbiani, S. Tubafard, O. Blacque, P. Anstaett, A. Felgenträger, T. Maisch, L. Spiccia, G. Gasser, J. Med. Chem. 2014, 57, 7280.

[28] T. Gianferrara, C. Spagnul, R. Alberto, G. Gasser, S. Ferrari, V. Pierroz, A. Bergamo, E. Alessio, ChemMedChem 2014, 9, 1231.

[29] A. Bergamo, C. Gaiddon, J. H. M. Schellens, J. H. Beijnen, G. Sava, J. Inorg. Biochem. 2012, 106, 90.

[30] A. Levina, A. Mitra, P. A. Lay, Metallomics 2009, $1,458$.

[31] R. Trondl, P. Heffeter, C. R. Kowol, M. A Jakupec, W. Berger, B. K. Keppler, Chem. Sci. 2014, 5, 2925

[32] C. G. Hartinger, M. A. Jakupec, S. ZorbasSeifried, M. Groessl, A. Egger, W. Berger, H. Zorbas, P. J. Dyson, B. K. Keppler, Chem Biodivers. 2008, 5, 2140

[33] G. Sava, S. Zorzet, C. Turrin, F. Vita, M. Soranzo, G. Zabucchi, M. Cocchietto, A. Bergamo, S. DiGiovine, G. Pezzoni, L. Sartor, S. Garbisa, Clin. Cancer Res. 2003, 9, 1898.

[34] A. Weiss, R. H. Berndsen, M. Dubois, C. Muller, R. Schibli, A. W. Griffioen, P. J. Dyson, P. Nowak-Sliwinska, Chem. Sci. 2014, 5, 4742.

[35] F. Kratz, M. Hartmann, B. Keppler, L. Messori, J. Biol. Chem. 1994, 269, 2581

[36] L. E. H. Paul, B. Therrien, J. Furrer, Org Biomol. Chem. 2015, 13, 946.
[37] G. C. Vougioukalakis, A. I. Philippopoulos, T. Stergiopoulos, P. Falaras, Coord. Chem. Rev. 2011, 255, 2602.

[38] V. Fernandez-Moreira, F. L. Thorp-Greenwood, M. P. Coogan, Chem. Commun. 2010, 46, 186.

[39] M. P. Coogan, V. Fernandez-Moreira, Chem. Commun. 2014, 50, 384-399.

[40] L. Salassa, Eur. J. Inorg. Chem. 2011, 4931.

[41] M. R. Gill, H. Derrat, C. G. W. Smythe, G. Battaglia, J. A. Thomas, ChemBioChem 2011, $12,877$.

[42] M. R. Gill, J. A. Thomas, Chem. Soc. Rev. 2012 , $41,3179$.

[43] N. L. Kilah, E. Meggers, Aus. J. Chem. 2012 , $65,1325$.

[44] A. E. Friedman, J. C. Chambron, J. P. Sauvage, N. J. Turro, J. K. Barton, J. Am. Chem. Soc. 1990, 112, 4960

[45] Y. Jenkins, A. E. Friedman, N. J. Turro, J. K. Barton, Biochemistry 1992, 31, 10809.

[46] V. Pierroz, T. Joshi, A. Leonidova, C. Mari, J. Schur, I. Ott, L. Spiccia, S. Ferrari, G. Gasser, J. Am. Chem. Soc. 2012, 134, 20376.

[47] T. Joshi, V. Pierroz, S. Ferrari, G. Gasser, ChemMedChem 2014, 9, 1419-

[48] R. R. Allison, C. H. Sibata, Photodiagn. Photodyn. 2010, 7, 61.

[49] A. E. O'Connor, W. M. Gallagher, A. T. Byrne, Photochem. Photobiol. 2009, 85, 1053.
[50] S. Bonnet, Comments Inorg. Chem. 2014, DOI: 10.1080/02603594.2014.979286.

[51] S. L. H. Higgins, K. J. Brewer, Angew. Chem., Int. Ed. 2012, 51, 11420

[52] M. C. DeRosa, R. J. Crutchley, Coord. Chem. Rev. 2002, 233, 351 .

[53] R. K. Pandey, C. K. Herman, Chem. Ind (London) 1998, 18, 739.

[54] O. J. Stacey, S. J. A. Pope, RSC Adv. 2013, 3, 25550.

[55] S. Swavey, 'Ruthenium Complexes as Photosensitizers: New Possibilities in Photodynamic Therapy', Nova Science Publishers, Inc.: New York, 2011.

[56] I. Ott, C. Biot, C. G. Hartinger, in 'Inorganic Chemical Biology', Ed. G. Gasser, Wiley-VCH Verlag GmbH \& Co. KGaA, 2014.

[57] U. Schatzschneider, Eur. J. Inorg. Chem. 2010, 1451

[58] N. J. Farrer, L. Salassa, P. J. Sadler, Dalton Trans. 2009, 10690.

[59] H. Yin, M. Stephenson, J. Gibson, E. Sampson, G. Shi, T. Sainuddin, S. Monro, S. A McFarland, Inorg. Chem. 2014, 53, 4548.

[60] R. Lincoln, L. Kohler, S. Monro, H. Yin, M. Stephenson, R. Zong, A. Chouai, C. Dorsey, R. Hennigar, R. P. Thummel, S. A. McFarland, $J$. Am. Chem. Soc. 2013, 135, 17161. 